\title{
EXTRACTION OF BLUE ICE AREA USING ALBEDO VALUE DERIVED FROM LANDSAT- 8 SATELLITE DATA
}

\author{
Alvarinho J. Luis ${ }^{1,}$ *, Prashant H. Pandit ${ }^{2 *}$, Shridhar D. Jawak ${ }^{1,3}$ \\ ${ }^{1}$ Earth System Science Organization - National Centre for Antarctic and Ocean Research, India - alvluis@ncaor.gov.in \\ ${ }^{2}$ Department of Natural Resources, TERI University, New Delhi, India - sh.prashantpandit@ gmail.com \\ ${ }^{3}$ Svalbard Integrated Arctic Earth Observing System (SIOS), SIOS Knowledge Centre, University Centre in Svalbard \\ Longyearbyen, Svalbard, Norway - shridhar.jawak@gmail.com
}

Commission V, SS: Atmosphere, Ocean, Weather and Climate

KEY WORDS: Blue Ice, Landsat-8, Albedo, Polar record Glacier, Image Processing

Albedo is one of the most significant measures for the expansion of BIAs.

\begin{abstract}
:
Blue Ice Areas (BIAs) or bare ice areas are zones of glacier where surface mass balance is negative, sublimation forms the major ablation process and surface albedo is relatively small. Exceptionally dry and windy meteorological conditions over Antarctica favor the formation of large areas of net ablation on the ice sheet leading to formation of BIRs (Schytt, 1961). BIAs are major source of drinking water to research stations and serve as runways for airplanes in Antarctica. This study has been conducted on the Polar Record Glacier (PRG), Princess Elizabeth Land, East Antarctica, where more than $30 \%$ of area is covered by BIAs. The BIAs are extracted and estimated using the value of albedo which is the fraction of solar energy reflected from the surface back to space. A surface having a higher (lower) reflectivity occupies higher (lower) albedo. With an average value of blue ice albedo (also known as bare ice) of 0.55 , it ranges from 0.52 to 0.66 , due to its geographical area, katabatic wind and wind patterns, the direction of ice flow, rate of sublimation and ablation, surface temperature, etc. The extent of BIAs also depends upon climate and seasonal changes. Albedo is calculated using the Level-1 product of Landsat, this data product (images) is processed according to standard parameters such as Geo-referencing, re-sampling, re-projection and north-up image re-orientation. These data (Digital Numbers) were further calibrated to standard pixel value using multiplicative and additive rescaling factors from metadata provided with the Level-1 product and scaled for absolute reflectance. A further algorithm was applied to get albedo from Landsat- 8 dataset. After processing the data, we detected some error in a few pixels, $(\sim 20)$ which was normalized by using band math. Our result indicates that the range of albedo for the BIAs is decreasing (more surface absorption of solar radiation), which subsequently could promote warming of surface due to increase in the surface temperature. The decreasing rate of albedo suggest the possibility of less reflection of radiation to the atmosphere, more melting which leads to depletion in the BIAs. The carry home message is that the variation in different parameters like albedo of the glacier causes significant variation in the surface area and spatial extent of BIAs.
\end{abstract}

\section{INTRODUCTION}

Blue-ice areas (BIAs), which account for $1 \%$ of the Antarctic surface area (Bintanja, 1999), are important because of their surface characteristics- they are flat, smooth and hard. Eventhough their area is too small to play an important role in the total surface mass balance, they can be quite important on regional scale for mass balance and therfore for the ice flow. Blue ice, also called bare ice, is mostly found in the Antarctic mountainous terrain which creates disturbance in the flow of katabatic wind. BIAs are found on an ice field on a glacier, ice shelf or ice sheet where ablation process is greater than the snowfall. It has lower albedo so the surface looks comparatively dark. The ice surface acts like a filter, absorbs maximum of the red and green radiation, and reflects maximum blue wavelength so that the ice exhibits a blue colour (Curzio et al., 2008). BIAs are regions where sublimation forms the main ablation process with negative surface mass balance and where surface albedo is very low in comparison to pure snow. The local wind field determines the latent and sensible heat fluxes over blue ice which are considerably larger than over snow (by a factor of 3), partly because relative humidities are much lower (by 15-20\% on average) over BIAs (Bintanja, 2000). Moreover, the cloudiness also determines the radiation balance of BIAs. Their extent varies frequently, because of weather, seasonal effect or climate change. Because of sensitivity in its extending factor, it is an important parameter for an environmentalist to monitor climate by measuring meteorological factor, surface temperature, air temperature, snow, albedo, etc. BIA fields in Antarctica are well known as source regions for meteorites (Koeberl, 1990), as some BIAs act as meteorite traps (Cassidy et al., 1992). Studies have found more than 30000 meteorites on Antarctic blue ice areas. Many Antarctic BIAs are important stranding surfaces for a large number of meteorites (Whillans and Cassidy, 1983). The age of the surface ice has been determined by radiogenic and meteorite exposure dating to be typically between 10,000 to 200,000 years, although some meteorites have terrestrial ages of more than 2 million years (Bintanja, 1999). In high altitude BIAs, melting does not occur and the areas contain ancient ice at the surface in essentially pristine state. This valuable source of paleoclimatic data has not been utilized to date, largely because of difficulties in dating the ice (Liston et al., 2005). The bare, rippled ice surface of BIAs is also considered useful for airfield purposes (Mellor and Swithinbank, 1989) and Russians are using as an airplane runway. Ice cores taken from BIAs revealed that very old ice

\footnotetext{
${ }^{*}$ Corresponding author
} 
were exposed at the surface (Nishiizumi et al., 1989), which can be exploited for paleoclimatic research. The ice exposed at BIAs was formed long ago in a distant accumulation zone and has since flowed towards the BIA (Whillans and Cassidy, 1983; Brown and Scambos, 2004).

The Lambert Glacier-Amery Ice Shelf, situated in East Antarctica, is one of the biggest glacial basins on Earth, with a drainage area of 1.38 million $\mathrm{km}^{2}$. Previous research has been reported that Lambert Glacier-Amery Ice Shelf has the biggest share of BIAs in Antarctica, accounting for about $23 \%$ of total BIAs in Antarctica (Liston and Winther 2005). Many remote sensing methods have been implemented to identify and map Antarctic BIAs.

BIAs can be easily identified by satellite remote sensing data, but small BIA patches can only be recognized with highresolution data. The mathematical ratio of satellite bands is one of the active techniques to get information about the surface and its properties because it emphasizes the albedo signal by reducing the effects of the slope. Standardization of pixel value can convert into radiance using method suggested by USGS (Jawak et al., 2015, 2016).

Albedo is the fraction of solar energy reflected from earth back to space, which ranges from 0 to 1 . It measures the capacity of the earth's surface in reflecting the sun's energy. The value of albedo indicates absorbing as well as reflecting capacity of the surface. Whenever the albedo values decrease, the reflectivity of a surface decreases. Absorption is inversely proportional to albedo index. Pure snow has a higher albedo and reflects almost $90-95 \%$ of sun's energy. After the snow melts its albedo decreases because of formation of shallow melt ponds. The albedo over Antarctic ponds was found to be ranging from 0.2 to 0.4. Most parts of Antarctica render albedo exceeds 0.6, whereas in few regions it goes down to 0.1. The mountainous region of eastern Antarctica has lower albedo because approximately $1 \%$ of its region is occupied by BIAs. Albedo for blue ice regions ranges from 0.52 to 0.66 , sometimes it decreases and increases because of its internal and external properties. The albedo of BIAs depends on geographical location, the direction of ice flow, wind pattern, etc. According to Bintanja (1997), the average mean albedo of blue ice is 0.55 . Because of lower albedo, it absorbs twice as much of the sun's energy as snow. Many researchers provide different values for albedo for the blue ice region, depending on their study area and ground observation values.

\section{STUDY AREA}

The Polar Record Glacier (PRG) is located on Princess Elizabeth land, East Antarctica (Figure 1). PRG has an ice tongue that flows into Sandefjord Ice Bay. It is nearly $50 \mathrm{~km}$ southwest from the third Indian Antarctic Research Station Bharati, which is situated at the Larsemann Hills, East Antarctica. It is the biggest glacier that flows from the middle part of the Publication Ice Shelf between Meknattane Nunataks and Dodd Island. Roscoe (1952) who observed that the ice tongue is extended $35 \mathrm{kms}$ out into the open sea in 1937, $68 \mathrm{~km}$ into the open sea in 1947, with a velocity of around 3.3 $\mathrm{km} /$ year. Subsequently, Roscoe (1952) predicted that the tongue of the PRG would calve when it would encounter Amery Ice Shelf (AIS). Later, a study conducted in 1996 proved the facts claimed by Roscoe (1952). The study confirmed that the large iceberg calved away between 1980 and 1990. Earlier the PRG was more than $450 \mathrm{~km}^{2}$ but after several calving events, it decreased in size and remained at less than $300 \mathrm{~km}^{2}$. Latest study (Pandit et al., 2017) reveals that the PRG has an extended ice tongue, and the shape and orientation have been changed since the study of Roscoe (1952).

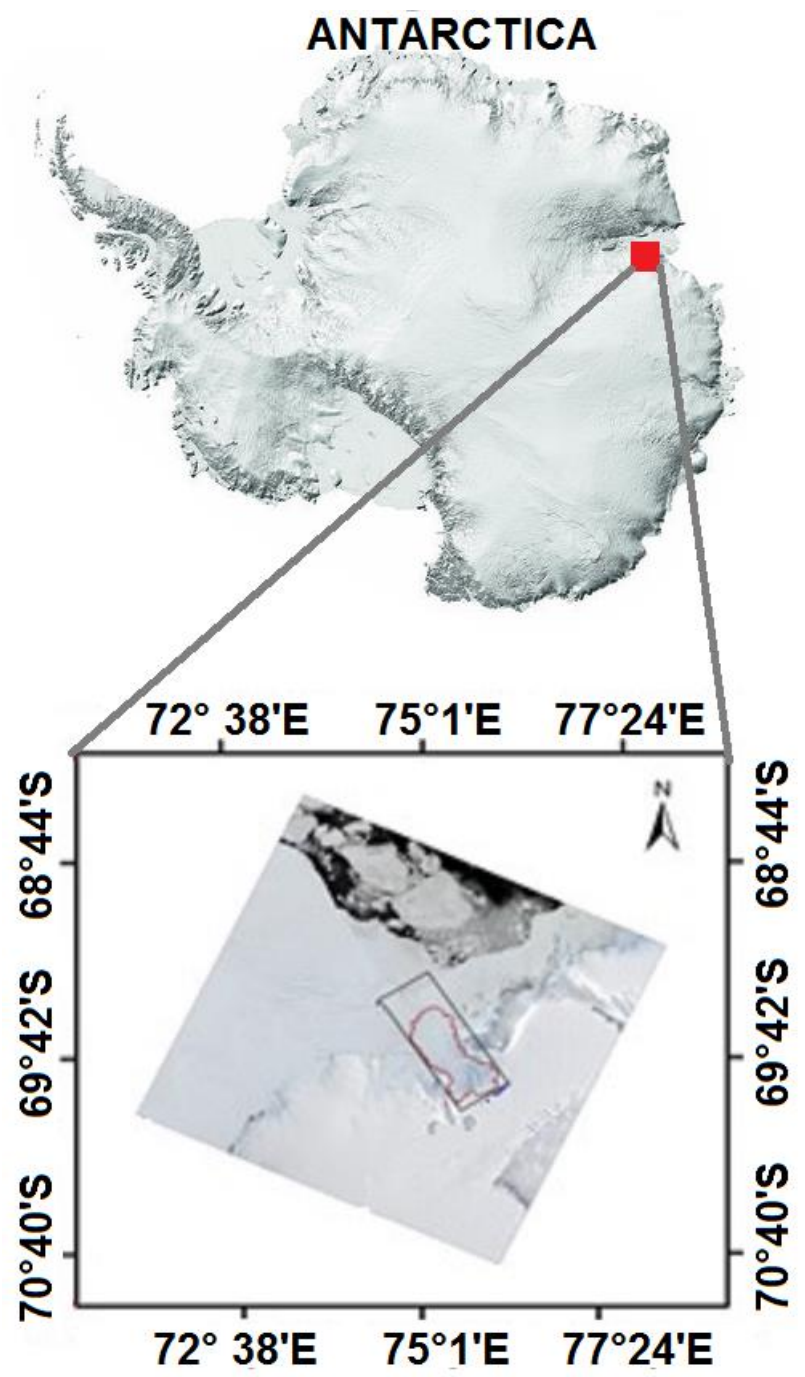

Figure 1: Geo-location of Polar Record Glacier, East Antarctica (top) and Landsat-8 imagery depicting the position and extent of the glacier (bottom).

\section{DATA AND MATERIALS}

Landsat- 8 satellite is a part of the Earth Resources Technology Satellite (ERTS) mission, later deployed for earth observation

(EO) purpose. It was launched in February 2013 with a temporal resolution of 16 days. In this study, we used multiple bands of Landsat- 8 . Landsat- 8 satellite imageries of different temporal resolutions were downloaded from the United State Geological Survey (USGS) website. Landsat-8 with a higher radiometric resolution is specifically useful for researchers working on cryosphere and polar remote sensing. Many glaciologists are using Landsat data for mapping glaciers, snow and ice. Landsat has the largest time series data available with incomparable spatial-spectral-temporal resolution. The presence of six spectral bands beyond the visible range of the 
electromagnetic (EMR) spectrum provides opportunities to monitor cryospheric features closely beyond the reach of human visibility. Spectral profiles of the blue band, have a peak in snow and ice area, and the presence of two bands of the blue spectrum (Band 1 and Band 2) are advantageous for monitoring the cryosphere. The band specification of Landsat sensor used for this study is illustrated in Table 1.

\begin{tabular}{|c|c|c|c|}
\hline Band & Wavelength $(\boldsymbol{\mu m})$ & Resolution $(\mathbf{m})$ & Spectral information \\
\hline $\mathbf{1}$ & $0.435-0.451$ & 30 & Coastal/Aerosol \\
\hline $\mathbf{2}$ & $0.452-0.512$ & 30 & Blue \\
\hline $\mathbf{3}$ & $0.533-0.590$ & 30 & Green \\
\hline $\mathbf{4}$ & $0.636-0.673$ & 30 & Red \\
\hline $\mathbf{5}$ & $0.851-0.879$ & 30 & NIR \\
\hline $\mathbf{6}$ & $1.566-1.651$ & 30 & SWIR-1 \\
\hline $\mathbf{7}$ & $2.107-2.294$ & 30 & SWIR-2 \\
\hline $\mathbf{8}$ & $0.503-0.676$ & 15 & Pan \\
\hline $\mathbf{9}$ & $1.363-1.384$ & 30 & Cirrus \\
\hline $\mathbf{1 0}$ & $10.60-11.19$ & 100 & TIRS-1 \\
\hline $\mathbf{1 1}$ & $11.50-12.51$ & 100 & TIRS-2 \\
\hline
\end{tabular}

Table 1. Landsat-8 Operational Land Imager (OLI) and Thermal Infrared Sensor (TIRS) bands.

\section{METHODOLOGY}

The methodology used in this study can be divided into a series of steps- starting with pre-processing of landsat- 8 imagery and ended-up with derivation of BIAs. In this study, albedo is calculated with the help of DN - albedo method. After calculating albedo, the threshold value is defined to extract BIAs. Establishment of the threshold and extraction of BIAs from albedo is performed in ArcMap with the help of model maker.

The Landsat- 8 OLI sensor data is very sensitive in comparison with Landsat TM and ETM+ data. It is because of the difference in a number of the bands present in both Landsat satellite series. Data are rescaled into 16-bit DNs, ranging from 0 to 65536 . Landsat-8 data was converted from DN to reflectance in a single step. Standardized DN is processed as ToA reflectance and radiometric error is minimized by dividing with sun angle. Albedo is derived by the procedure suggested by Liang, 2000 .

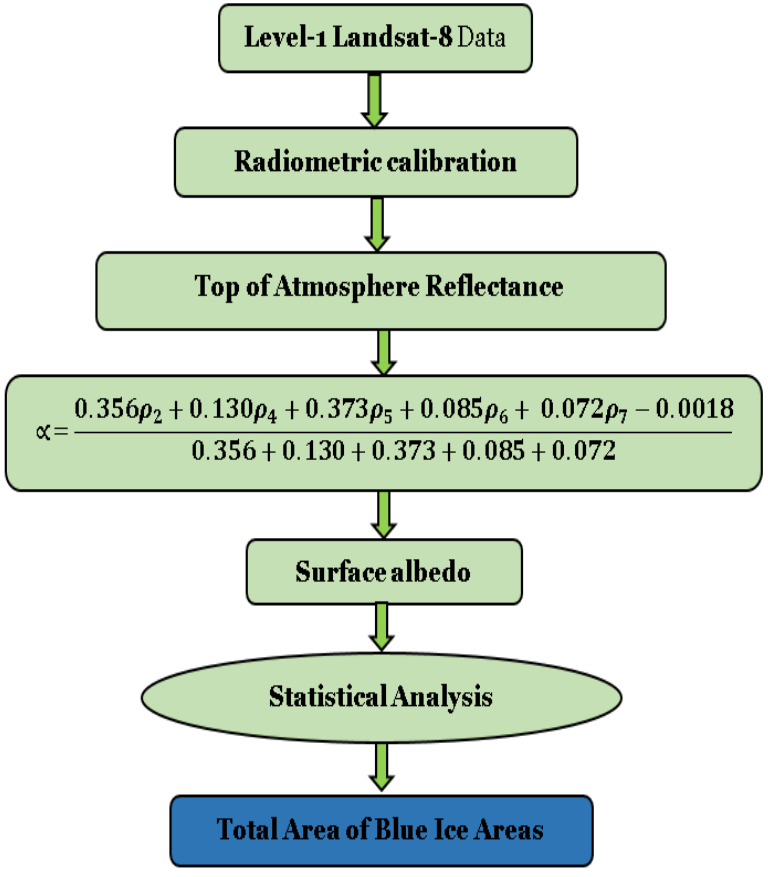

Statistical analysis is performed on the derived values of albedo. The mean and standard deviation (SD) are calculated for each

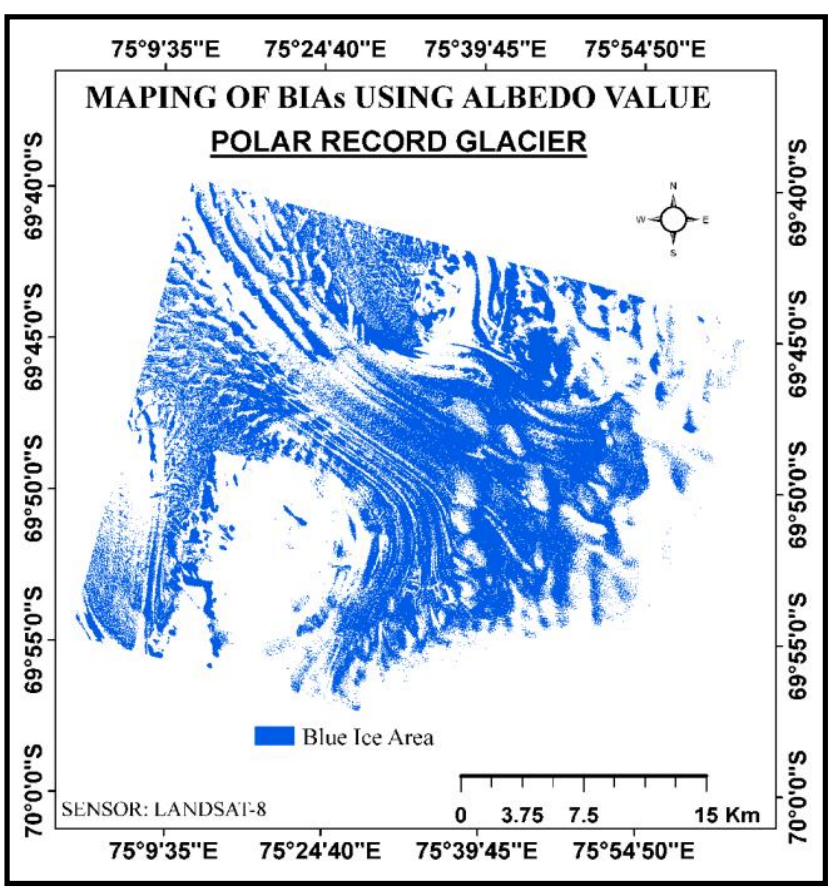

Figure 2: BIAs derived from albedo using Landsat-8 Imagery.

albedo dataset to quantify its dispersion of data values, where lower SD indicates that the data points tend to be close to the mean of the set of multiple imageries. The pixel that indicated BIAs is randomly picked up to its probabilistic truth significance. We also validated the derived area with the ground dataset, but owing few ground points of BIAs in comparison with the derived BIAs, it led to erroneous values.

\section{RESULT AND DISCUSSION}

It is found that BIAs and albedo are correlated. Temperature and albedo affect the variations in BIAs, which indicates that some other factors may also work in tandem with these processes. Sometimes variations can be easily seen within a week, month or in a year, but sometimes in decades. Multiple factors require to be measured to quantify changes in the cryosphere. BIAs are one of the sensitive regions over a glacier. Minute changes in atmosphere affect the total area of BIAs. In this study, we found that albedo for BIAs depict range between 0.52 and 0.66 .

\section{CONCLUSIONS}

Our study indicate that PRG of east Antarctica which earlier had an area $>450 \mathrm{~km}^{2}$ is now reduced to around $300 \mathrm{~km}^{2}$. This has occurred due to many ice calving events from its tongue. The range of albedo for the whole area shows a decreasing trend, which promotes an increase in the surface temperature. About $95 \%$ of solar radiation is reflected back to space by snow, but a decreasing albedo trend reveals less reflection of solar radiation, which increases surface temperature leading to melting of snow. As the BIA sensitivity varies over glacier regions, minute changes in atmosphere affect the total area of

Figure 3: Protocol for deriving blue ice areas from Landsat-8 by computing albedo. 
BIAs. The temporal variability of a glacier depends on upon many factors; major factors are glacier surface temperature, surgace mass balance, glacier flow velocity (Ligtenberg et al., 2013), albedo, etc. The impact of these factors over BIAs should be precisely correlated to identify exact relations. This preliminary work will build the foundation for long-term monitoring of changes in Antarctic BIAs, which could be indicative of global changes, and will accumulate both data and experience for further studies.

\section{ACKNOWLEDGEMENTS}

The authors would like to thank USGS-Earth explorer for providing the imagery used in this study. We also acknowledge Dr. M. Ravichandran, Director, ESSO-NCAOR, for his encouragement and motivation for this research. The experiment, validation, manuscript preparation, and editing of the manuscript was conducted at the ESSO-NCAOR.

\section{REFERENCES}

Bintanja, R., 2000. Surface heat budget of Antarctic snow and blue ice: Interpretation of spatial and temporal variability. Journal of Geophysical Research: Atmospheres, 105(D19), pp 24,387-24,407.

Bintanja, R., 1999. On the glaciological, meteorological, and climatological significance of Antarctic blue ice areas. Reviews of Geophysics, 37(3), pp.337-359.

doi: https://doi.org/10.1029/1999rg900007

Bintanja, R., Jonsson, S. and Knap, W., 1997. The annual cycle of the surface energy balance of Antarctic blue ice. Journal of Geophysical Research: Atmospheres, 102(D2), pp.1867-1881. doi: https://doi.org/10.1029/96jd01801

Brown, I. and Scambos, T., 2004. Satellite monitoring of blueice extent near Byrd Glacier, Antarctica. Annals of Glaciology, 39, pp.223-230.

doi: https://doi.org/10.3189/172756404781813871

Cassidy, W., Harvey, R., Schutt, J., Delisle, G. and Yanai, K., 1992. The meteorite collection sites of Antarctica. Meteoritics, 27(5), pp.490-525.

doi: https://doi.org/10.1111/j.1945-5100.1992.tb01073.x

Curzio, P., Folco, L., Ada Laurenzi, M., Mellini, M. and Zeoli, A., 2008. A tephra chronostratigraphic framework for the Frontier Mountain blue-ice field (northern Victoria Land, Antarctica). Quaternary Science Reviews, 27(5-6), pp.602-620. doi: https://doi.org/10.1016/j.quascirev.2007.11.017

Jawak, S. and Luis, A., 2016. Application of high-resolution multispectral data for mapping blue ice areas in the Antarctic environment. Land Surface and Cryosphere Remote Sensing III. doi: https://doi.org/10.1117/12.2222770

Jawak, S., Devliyal, P. and Luis, A., 2015. A Comprehensive Review on Pixel Oriented and Object-Oriented Methods for Information Extraction from Remotely Sensed Satellite Images with a Special Emphasis on Cryospheric Applications. Advances in Remote Sensing, 04(03), pp.177-195.

doi: https://doi.org/10.4236/ars.2015.43015
Jevrejeva, S., Moore, J., Woodworth, P. and Grinsted, A., 2005. Influence of large-scale atmospheric circulation on European sea level: results based on the wavelet transform method. Tellus A: Dynamic Meteorology and Oceanography, 57(2), pp.183193. doi: https://doi.org/10.3402/tellusa.v57i2.14609

Koeberl, C., 1990. Dust bands in blue ice fields in Antarctica and their relationship to meteorites and ice. In Antarctic Meteorite Stranding Surfaces (p. 70).

Liang, S., 2001. Narrowband to broadband conversions of land surface albedo I. Remote Sensing of Environment, 76(2), pp.213-238. doi: https://doi.org/10.1016/s0034-4257(00)002054

Liston, G. and Winther, J., 2005. Antarctic Surface and Subsurface Snow and Ice Melt Fluxes. Journal of Climate, 18(10), pp.1469-1481. doi: https://doi.org/10.1175/jcli3344.1

Mellor, M. and Swithinbank, C., 1989. Airfields on Antarctic glacier ice (No. CRREL-89-21). Cold regions research and engineering lab hanover $n h$.

Nishiizumi, K., Elmore, D. and Kubik, P., 1989. Update on terrestrial ages of Antarctic meteorites. Earth and Planetary Science Letters, 93(3-4), pp.299-313. doi: https://doi.org/10.1016/0012-821x(89)90029-0

Pandit, P.H, Jawak, S.D and Luis, A., 2017. 38th Asian Conference on Remote Sensing (ACRS 2017): Space Applications: Touching Human Lives. In: ACRS. [online] Asian Association on Remote Sensing (AARS).

Available at: http://a-a-r-s.org/acrs/index.php/acrs/acrsoverview/proceedings 1 ? view=publication $\&$ task=show $\&$ id $=311$ 0 (accessed on 18 July 2018).

Roscoe, J.H., 1952. Contributions to the study of Antarctic surface features by photogeographical methods (Doctoral dissertation).

Stonehouse, B., 1991. Blue Ice Airfields Airfields on Antarctic glacier ice. M. Mellor and C. Swithinbank 1989. Springfield Va., US Army Cold Regions Research and Engineering Laboratory (CRREL Report 89-21). 105 p, illustrated, soft cover. Polar Record, 27(160), p.67. doi: https://doi.org/10.1017/s0032247400020027

Whillans, I. and Cassidy, W., 1983. Catch a Falling Star: Meteorites and Old Ice. Science, 222(4619), pp.55-57. doi: https://doi.org/10.1126/science.222.4619.55 